\title{
Artigo
}

\section{Notas sobre a utilização de agrotóxicos em Santa Catarina e no Brasil (2009-2017)}

\author{
Shaiane Carla Gaboardi
}

\begin{abstract}
Resumo
O Brasil tem se destacado como um dos maiores compradores e consumidores de agrotóxicos do mundo. No estado de Santa Catarina, a utilização de agrotóxicos configura-se como um problema ainda pouco abordado por pesquisas e pouco divulgado na mídia. Este artigo visa a traçar um panorama da utilização de agrotóxicos na Microrregião de Rio do Sul, bem como no estado de Santa Catarina, e no Brasil como um todo. A metodologia utilizada consistiu na coleta e na análise de dados de órgãos oficiais federais e estaduais como IBGE, IBAM A e CIDASC. Posteriormente, foi realizada a produção de mapas temáticos e gráficos. A partir disso, concluiu-se que, num período de nove anos, o volume comercializado de agrotóxicos aumentou, aproximadamente, 80\%no Brasil. Em Santa Catarina, o aumento foi de 107\% Percebeuse que 0 agrotóxico mais utilizado foi o Glifosato, classificado pela Organização Mundial da Saúde como provavelmente cancerígeno para os seres humanos, e pelo IBAMA, como produto perigoso ao meio ambiente. Tanto no estado em questão como no país inteiro, os produtos classificados nas categorias perigoso e muito perigoso ao meio ambiente correspondem a, aproximadamente, 93\%das vendas totais de agro tóxicos. Isso ocorre em virtude da estrutura político-econô mica que dá sustentação ao agronegócio, desde a mídia hegemônica, grupos transnacionais, "cooperativas" e outros atores.
\end{abstract}

Palavras-chave: Agrotóxicos; Ambiente; Santa Catarina.

\section{Some remarks on the use of pesticides in Santa Catarina and Brazil (2009-2017)}

\begin{abstract}
Brazil has stood out as one of the largest buyers and consumers of pesticides in the world. In the state of Santa Catarina, the use of pesticides is a problem which researchers seldom approach and is poorly
\end{abstract}


showcased by the media. This paper aims to describe an overview of the use of pesticides in the Microregion of Rio do Sul/SC, as well as in the state of Santa Catarina and Brazil as a whole. The applied methodology consisted on the collection and analysis of data from federal and state official agencies, such as IBGE, IBAMA and CIDASC. Subsequently, we designed graphs and thematic maps. From this, we concluded that, in a nine-year interval, the marketed volume of pesticides has increased around $80 \%$ in Brazil. In Santa Catarina, the increase has been of $107 \%$ The most used pesticide is glyphosate, classified by World Health Organization as probably carcinogenic for human beings, and by IBAMA as a dangerous product to the environment. In both Brazil and in Santa Catarina, the products classified in the catego ries Dangerous and Very Dangerous to the environment correspond to around $93 \%$ of the total sales of pesticides. This happens due to the political-economic structure that supports agribusiness, from the hegemonic media, to transnational groups, to "cooperatives" and other actors.

Keywords: Pesticides; Environment; Santa Catarina.

\title{
Notas sobre la utilización de pesticidas en Santa Catarina y en Brasil (2009-2017)
}

\begin{abstract}
Resumen
Brasil se ha destacado como uno de los mayores compradores y consumidores de pesticidas del mundo. En el estado de Santa Catarina la utilización de pesticidas se configura en un problema aún poco abordado por investigaciones y poco divulgado en los medios de comunicación. Este artículo busca trazar un panorama de la utilización de pesticidas en Brasil, en Santa Catarina, así como en la M icrorregión de Rio do Sul / SC. La metodología utilizada consistió en la colecta y análisis de datos de órganos oficiales federales y estatales como IBGE, IBAM A y CIDASC. Posteriormente, se realizó la producción de mapas temáticos y gráficos. A partir de eso, se concluyó que en un período de nueve años, el volumen comercializado de pesticidas aumentó aproximadamente el 80\%en Brasil. En Santa Catarina, el aumento fue del $107 \%$ El pesticida más utilizado es el Glifosato, clasificado por la Organización M undial de la Salud como probablemente cancerígeno para los seres humanos, y por el IBAMA, co mo producto peligroso al medio ambiente. Tanto en Brasil como en Santa Catarina, los productos clasificados en las categorías Peligrosas y Muy Peligrosas al medio ambiente, corresponden a aproximadamente el $93 \%$ de las ventas totales de pesticidas. Esto ocurre en virtud de la estructura político-económica que da sustentación al agronegocio, desde los medios de comunicación hegemónicos, grupos transnacionales, "cooperativas" y otros actores.
\end{abstract}

Palabras clave: Pesticidas; Medio ambiente; Santa Catarina. 


\section{Introdução}

0 modelo agropecuário predominante na maior parte do mundo encontra-se amplamente vinculado ao desenvolvimento científico e tecnológico de produtos variados, entre eles, os insumos químicos, tais como fertilizantes, herbicidas, inseticidas, fungicidas entre tantos outros biocidas. 0 processo de modernização da agricultura, intensificado entre as décadas de 1960 e 1970, através de um projeto denominado "Revolução Verde", foi responsável por diversas mudanças produtivas, econômicas, ambientais e sociais.

No Brasil, incentivos governamentais promoveram a modernização da agricultura, a partir da década de 1970, por meio dos Planos Nacionais de Desenvolvimento, os quais incentivaram 0 acesso a novas tecnologias produtivas e a instalação de empresas ligadas ao setor agropecuário. Assim, o país tornou-se um dos maiores produtores e exportadores de gêneros alimentícios diversos, com destaque para a soja, o milho e as carnes de origem bovina, suína e avícola.

0 aumento da produção pautada em monoculturas em resposta à demanda externa de commodities agrícolas, também, levou à expansão do uso de agrotóxicos. Segundo informações do Ministério do Meio Ambiente e do Dossiê produzido pela Associação Brasileira de Saúde Coletiva (ABRASCO), atualmente, o Brasil é o maior consumidor de agrotóxicos do mundo. Entre 1985 e 2015 houve um aumento de 700\%no consumo de agrotóxicos no Brasil. Contudo, a área agrícola cresceu 78\%nesse mesmo período (SPADOTO; GOMES, 2015). Dados do Instituto Brasileiro do M eio Ambiente e dos Recursos Naturais Renováveis (IBAM A) revelam que, desde 2014, o Brasil tem utilizado mais de 500 mil toneladas de agrotóxicos por ano.

O estado de Santa Catarina tem se destacad o como um dos maiores consumidores desses produtos e, atualmente, encontra-se entre os dez estados que mais consomem agrotóxicos no país. 0 que chama atenção é que, apesar do estado ter aumentado o consumo de agrotóxicos em 107\% em nove anos (entre 2009 e 2017), a utilização de 
agrotóxicos configura-se como um problema ainda pouco abordado por pesquisas e pouco divulgado na mídia.

Dessa forma, este artigo, resultado de uma pesquisa desenvolvida com o apoio do Instituto Federal Catarinense campus Ibirama, em parceria com o Grupo de Estudos Territoriais da Universidade Estadual do Oeste do Paraná, busca traçar um panorama da utilização de agrotóxicos na Microrregião onde o campus está inserido, bem como no estado de Santa Catarina, tendo em vista que esses produtos desencadeiam alto risco de contaminação ambiental e para a saúde humana.

\section{Metodologia}

A metodologia utilizada para a realização do artigo consistiu na coleta e na análise de dados de órgãos oficiais federais e estaduais, como Instituto Brasileiro de Geografia e Estatística (IBGE), Instituto Brasileiro do Meio Ambiente e dos Recursos Naturais Renováveis (IBAMA) e Companhia Integrada de Desenvolvimento Agrícola de Santa Catarina (CIDASC).

Nessa perspectiva, este artigo se propõe a ser uma aproximação à problemática dos agrotóxicos em Santa Catarina, utilizando apenas dados secundários. Admite-se que trabalhos de campo poderiam ter sido úteis para maior detalhamento da pesquisa, mas não houve recursos para esta possibilidade. Ademais, investir no levantamento de dados oficiais é fundamental para dar início a qualquer investigação, possibilitando mapear o contexto em que a microrregião, o estado e até mesmo o país está inserido.

Assim, a partir da sistematização dos dados acerca da comercialização de agrotóxicos, publicados pelo IBAM A (2018) e pelo IBGE (2017), foi realizada a produção de mapas temáticos e gráficos com a finalidade de espacializar e facilitar a visualização das informações obtidas. Já os dados disponibilizados pela CIDASC so bre comercialização 
do ingrediente ativo Glifosato foram coletados manualmente de relatórios de controle de estoque, os quais ficam armazenados no Departamento Regional de Rio do Sul/SC.

Para a elaboração dos mapas, foi gerada uma base cartográfica com os estados brasileiros e outra base com os vinte municípios da M icrorregião de Rio do Sul, a partir do IBGE (2016), sistemas de coordenadas UTM, SIRGAS 2000. Os mapas base com coordenadas, orientação, escala e legenda, foram produzidos com a utilização do software de design gráfico Corel Draw ${ }^{\circledR}$.

As classes foram definidas conforme a necessidade de cada conjunto de dados de maneira a melhor expressar as informações quantitativas obtidas. Como os mapas representam informações distintas, optou-se por utilizar cores diferentes em cada mapa, com tonalidades que variam das mais fortes, para os dados mais expressivos (valores maiores), até tonalidades mais fracas, para os dados quantitativos menos expressivos (valores menores), de acordo com procedimentos metodológicos que costumam ser padrão no contexto da cartografia temática (M ARTINELLI, 1991; DUARTE, 2002). Os gráficos apresentados foram criados no software Microsoft Excel $\circledast$.

\section{Resultados}

A afirmação do agronegócio pautado na produção de monoculturas extremamente dependentes de insumos químicos, como soja, milho, cana-de-açúcar e algodão, tem sido responsável pelo crescimento exponencial do uso de agrotóxicos no país. Segundo o Sindicato Nacional da Indústria de Produtos para a Defesa Vegetal SINDIVEG (2018), as culturas antes mencionadas foram responsáveis por $81 \%$ dos agrotóxicos consumidos no Brasil em 2017, com destaque para a soja, que consumiu 52\% de todo o volume comercializado no referido ano, conforme se pode observar no Gráfico 1 
Gráfico 1: Brasil: agrotóxicos aplicados por cultura em 2017.

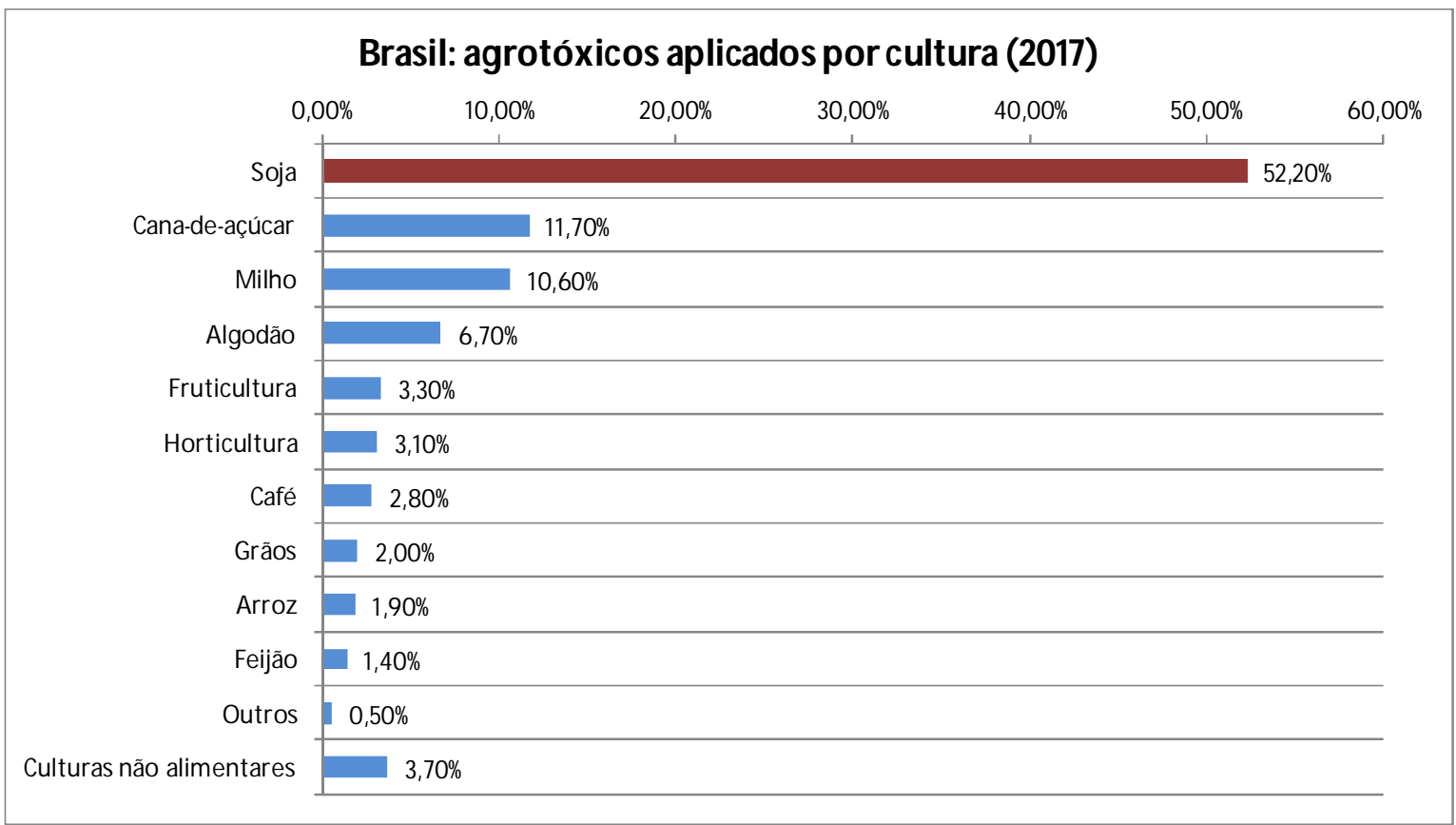

Fonte: SINDIVEG (2018). Org.: Autora, 2019.

Os dados divulgados pelo IBAMA em 2018 revelam que, desde 2014, o país ultrapassou a marca de uso de 500 mil toneladas por ano, conforme se pode observar no Gráfico 2. No período de nove anos retratado no gráfico, o aumento do volume comercializado de agrotóxicos foi de, aproximadamente, $80 \%$ sendo que, nas grandes regiões, há o destaque para o volume comercializado de agrotóxicos na região Norte, 0 qual foi de $538 \%$ o que pode significar o comprometimento de áreas de alta produtividade biológica primária. Nas demais regiões, o crescimento do volume comercializado, também, foi bastante significativo: Centro-Oeste (152\%), Nordeste (146\%), Sul (132\% e Sudeste (60\%). 
Gráfico 2: Total do volume comercializado de agrotóxicos no Brasil (2009-2017)

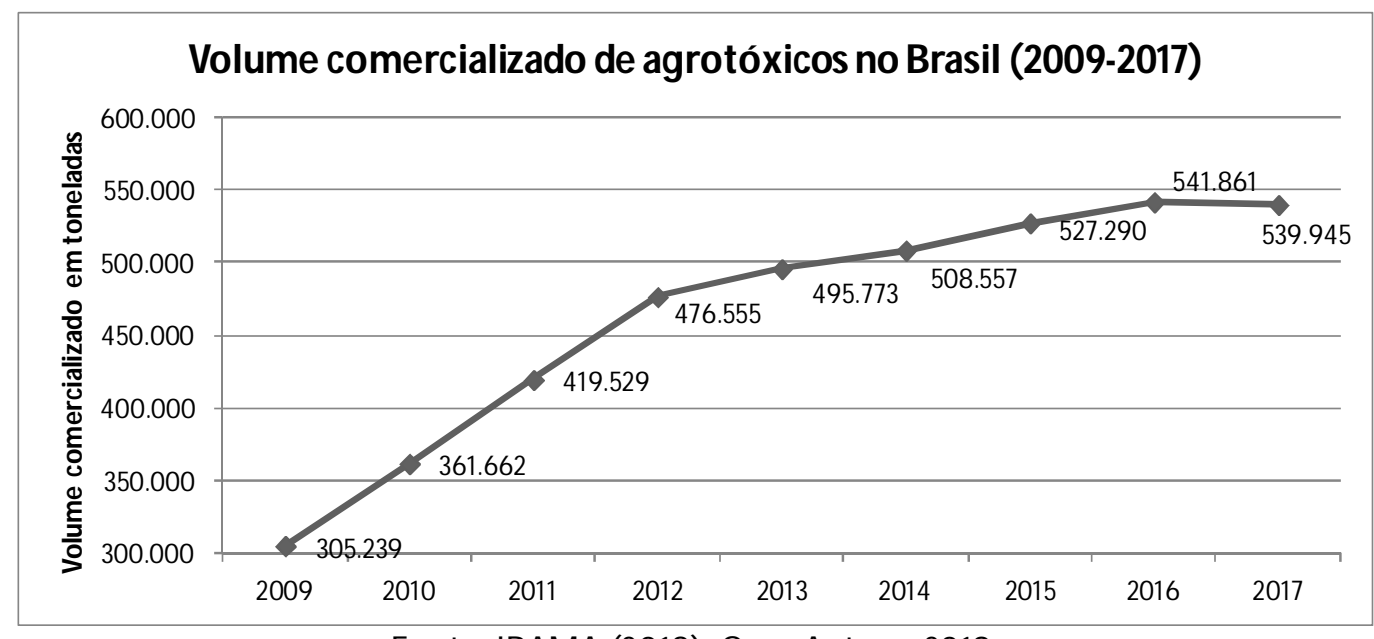

Fonte: IBAM A (2018). Org.: Autora, 2019.

0 volume comercializado por estado, no ano de 2017, pode ser visualizado no Mapa 1.

Mapa 1: Total do volume comercializado de agrotóxicos (2017)

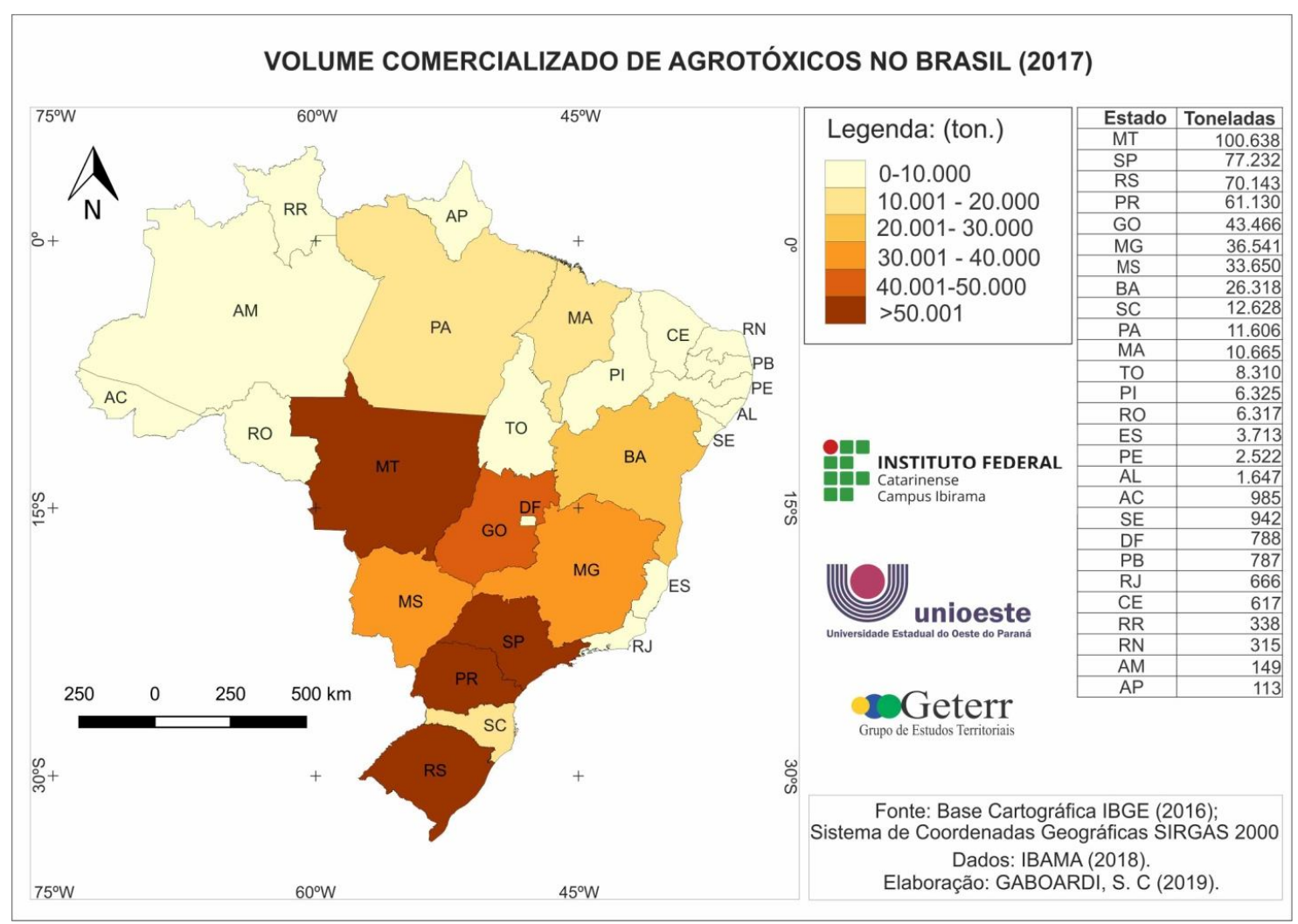

Fonte: IBAM A (2018). Org.: Autora, 2019.

AMBIENTES. Volume 1, Número 1, 2019, pp. 219-245. ISSN: 2674-6816 
Como demonstrado no Mapa 1, Mato Grosso é o estado que mais comercializou agrotóxicos no ano de 2017 (100.638 ton), seguido de São Paulo (77.232 ton), Rio Grande do Sul (70.143 ton) e Paraná (61130 ton). Na segunda classe dos que mais utilizaram agrotóxicos em 2017, está o estado de Goiás (43.466 ton); e na terceira classe, encontram-se M inas Gerais (36.541ton), M ato Grosso do Sul (33.650 ton) e Bahia (26.318 ton). Liderando a classe dos estados que comercializaram de 10 a 20 mil toneladas de agrotóxicos em 2017, está Santa Catarina com 12.628 toneladas.

Por mais que Santa Catarina ocupe o nono lugar em relação ao volume comercializado de agrotóxicos no Brasil, esse volume cresceu 107\%no período entre 2009 e 2017. Esse detalhamento pode ser visualizado no Gráfico 3.

Gráfico 3: Volume comercializado de agrotóxicos em Santa Catarina (2009-2017).

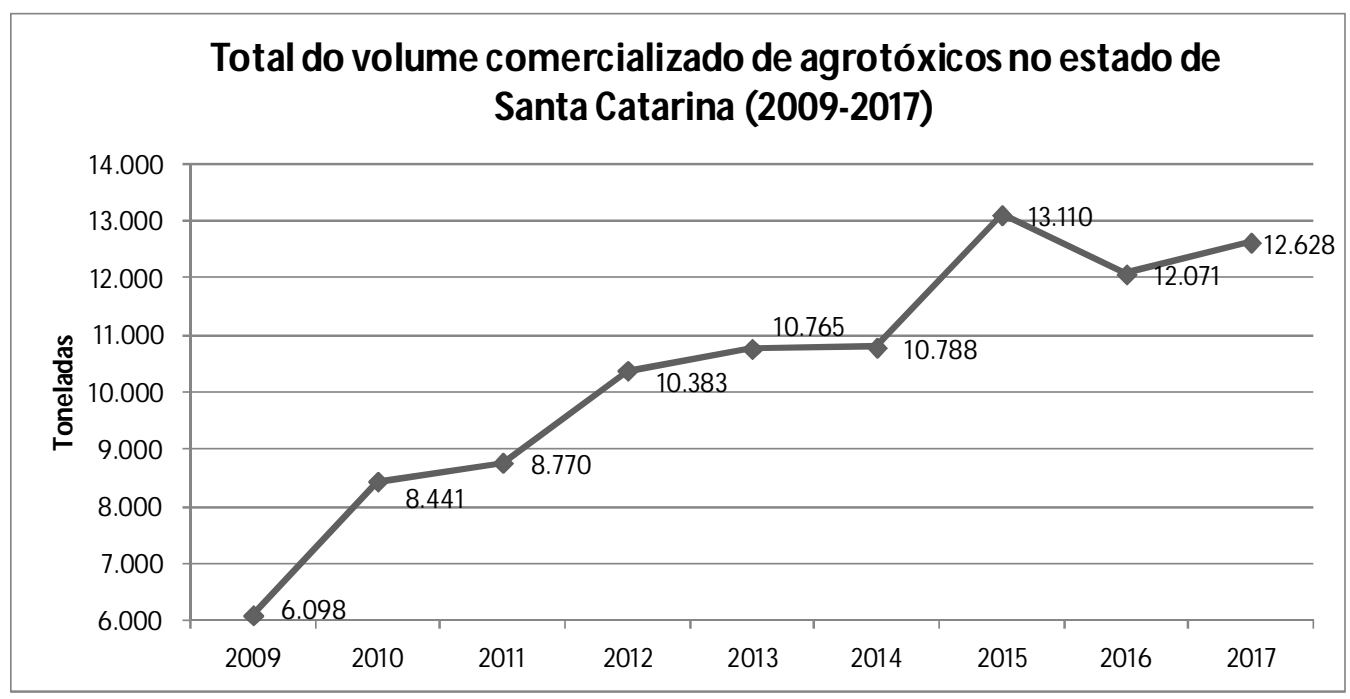

Fonte: IBAM A (2018). Org.: Autora, 2019.

O maior volume desses produtos foi destinado para as monoculturas de soja e milho, as quais ocuparam $74 \%$ da área colhida dos produtos da lavoura temporária no estado em 2017, conforme se pode observar no Gráfico 4. Essas lavouras estão extremamente dependentes de insumos químicos, entre eles, o ingrediente ativo Glifosato. 
Gráfico 4 -Área colhida dos produtos da lavoura temporária em Santa Catarina em 2017.

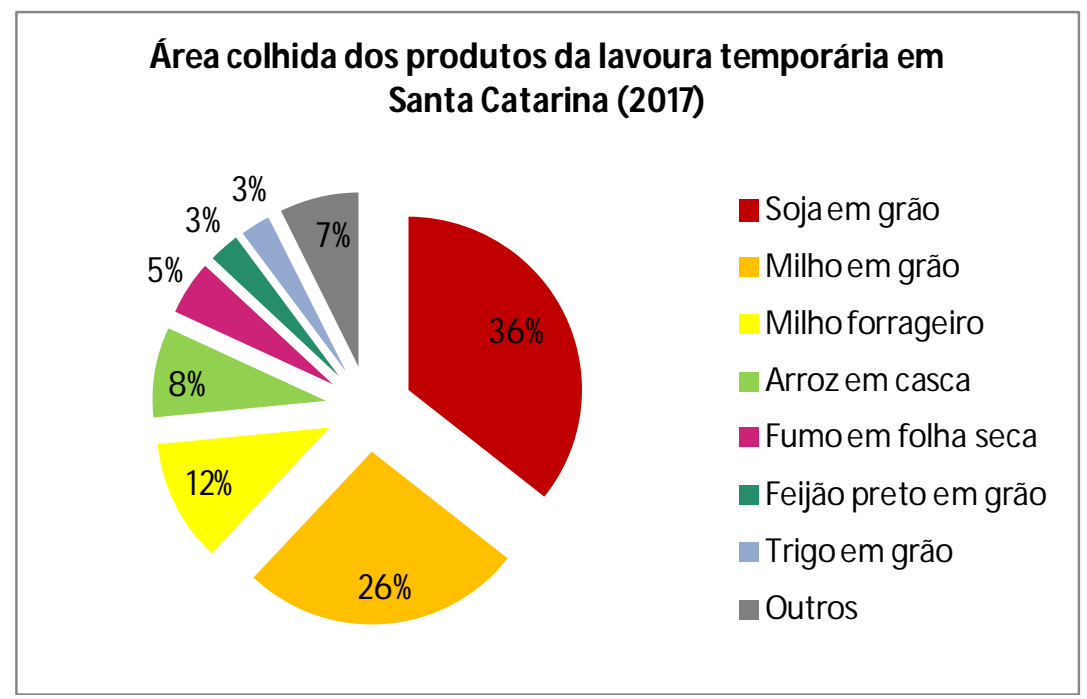

Fonte: Censo Agropecuário - IBGE (2017). Org.: Autora, 2019.

O Glifosato é o ingrediente ativo mais utilizado no Brasil (32\%das vendas totais), bem como em Santa Catarina (47\%das vendas totais). Esse produto é classificado como herbicida, o qual tem objetivo de eliminar plantas invasoras nas lavouras de monocultivo.

Um dos documentos mais recentes, publicado pela International Agency for Research on Cancer, intitulado "IARC M onographs on the evaluation of carcinogenic risks to humans - Some organophosphate insecticides and herbicides; Volume 12", admite 0 potencial cancerígeno do ingrediente ativo Glifosato em humanos e animais. Segundo a monografia, há evidências limitadas da carcinogenicidade do Glifosato em humanos, mas há positiva associação observada para linfoma non-Hodgkin. Assim, o ingrediente ativo foi enquadrado pela Organização Mundial da Saúde como provavelmente cancerígeno para os seres humanos. Já as experiências em animais determinaram evidências suficientes quanto à carcinogenicidade do Glifosato (IARC, 2017).

Entre os herbicidas, estão outros dois ingredientes ativos amplamente comercializados em Santa Catarina: o 2,4-D e a Atrazina. Como se pode observar no Gráfico 5, a comercialização de herbicidas teve um aumento significativo de $169 \%$ entre 2009 e 2017. 
Gráfico 5 - Comercialização de Agrotóxicos por Classe de Uso - Santa Catarina (2009-2017)

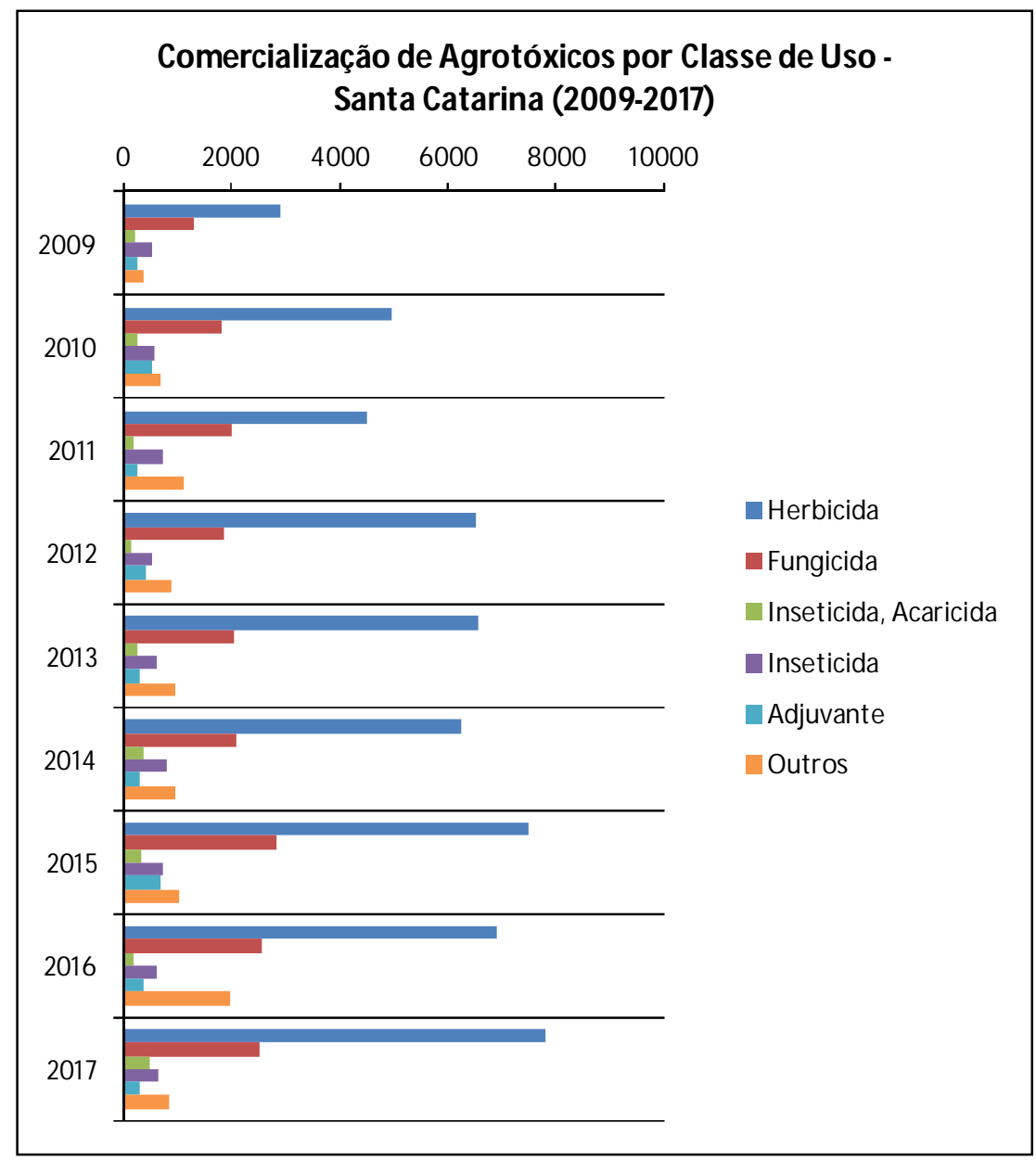

Fonte: IBAM A (2018). Org.: Autora, 2019.

Entre os fungicidas, o crescimento foi de $89 \%$ e o mais comercializado no estado de Santa Catarina, em 2017, foi o Mancozebe. Os ingredientes ativos com ação inseticida tiveram um aumento de $24 \%$ sendo o Acefato um dos mais comercializados. As demais classes de uso se mantiveram, praticamente, estáveis.

É preciso dar destaque, também, para um ingrediente ativo que está entre os dez mais vendidos na lista brasileira e na lista do estado de Santa Catarina o Dicloreto de Paraquate, conforme se pode observar no Gráfico 6. o Paraquate é um herbicida utilizado como dessecante em diversas culturas, como soja, milho e algodão. A Agência Nacional de Vigilância Sanitária (Anvisa) deliberou o banimento do produto no ano de 2017 pelos 
riscos decorrentes da sua utilização, como mutagenicidade e Doença de Parkinson (ANVISA, 2017). Contudo, após pressões do setor agropecuário, reverteu-se o processo de suspensão, estipulando um prazo de três anos para transição, mas permanece proibida a pulverização por aeronave. Esse fato demonstra como os interesses econômicos prevalecem em relação à saúde do trabalhador rural, dos consumidores e do ambiente.

Gráfico 6: Vendas por ingrediente ativo em Santa Catarina (2009-2017)

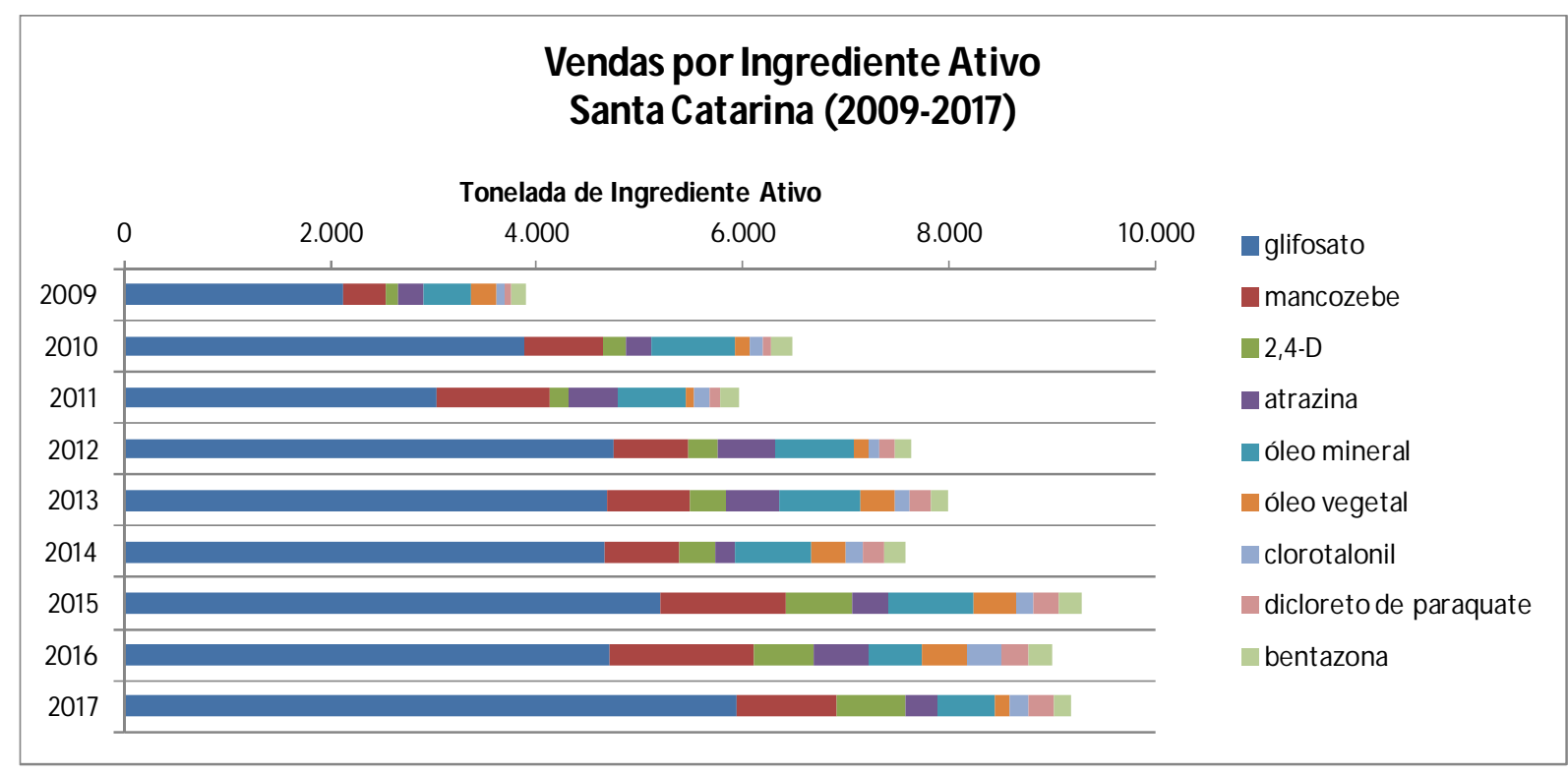

Fonte: IBAM A (2018). Org.: Autora, 2019.

Conforme estabelecido no Decreto nำ4.074/2002, o IBAM A é o órgão responsável por "realizar a avaliação ambiental dos agrotóxicos, seus componentes e afins, estabelecendo suas classificações quanto ao potencial de periculosidade ambiental" (BRASIL, 2002). Essa avaliação se baseia nas características do produto, como as propriedades físico-químicas e sua toxicidade para os organismos encontrados na natureza; o quanto o produto se acumula nos tecidos vivos; se persiste por muito tempo no ambiente; se consegue se deslocar no solo, ar ou água; e, ainda, são analisados os 
perigos de causar mutações, câncer, entre outras doenças, bem como o risco de comprometimento da reprodução de aves e mamíferos (IBAM A, 2010).

As classes são divididas da seguinte maneira: Classe I (Produto Altamente Perigoso), Classe II (Produto Muito Perigoso), Classe III (Produto Perigoso) e Classe IV (Produto Pouco Perigoso). Assim, todos os agrotóxicos registrados no Brasil possuem uma dessas classificações de periculosidade ambiental e essa informação é encontrada na bula dos produtos.

Conforme se observa no Mapa 2, os agrotóxicos que pertencem à Classe III (Perigoso ao meio ambiente) são os mais comercializados em todas as regiões do país. Esse fato ocorre porque os ingredientes ativos mais comercializados, como Glifosato e 2,4-D, são pertencentes à Classe III. Em segundo lugar, estão os produtos classificados na Classe II (M uito perigoso ao meio ambiente), pois a Atrazina, o Mancozebe e o Acefato pertencem a este grupo. Em terceiro lugar, são comercializad os os produtos da Classe IV (Pouco perigosos ao meio ambiente) e em quarto lugar são comercializados os produtos da Classe I (Altamente perigoso ao meio ambiente). 
Mapa 2: Volume comercializado de agrotóxicos por Classe de Periculosidade Ambiental, 2017.

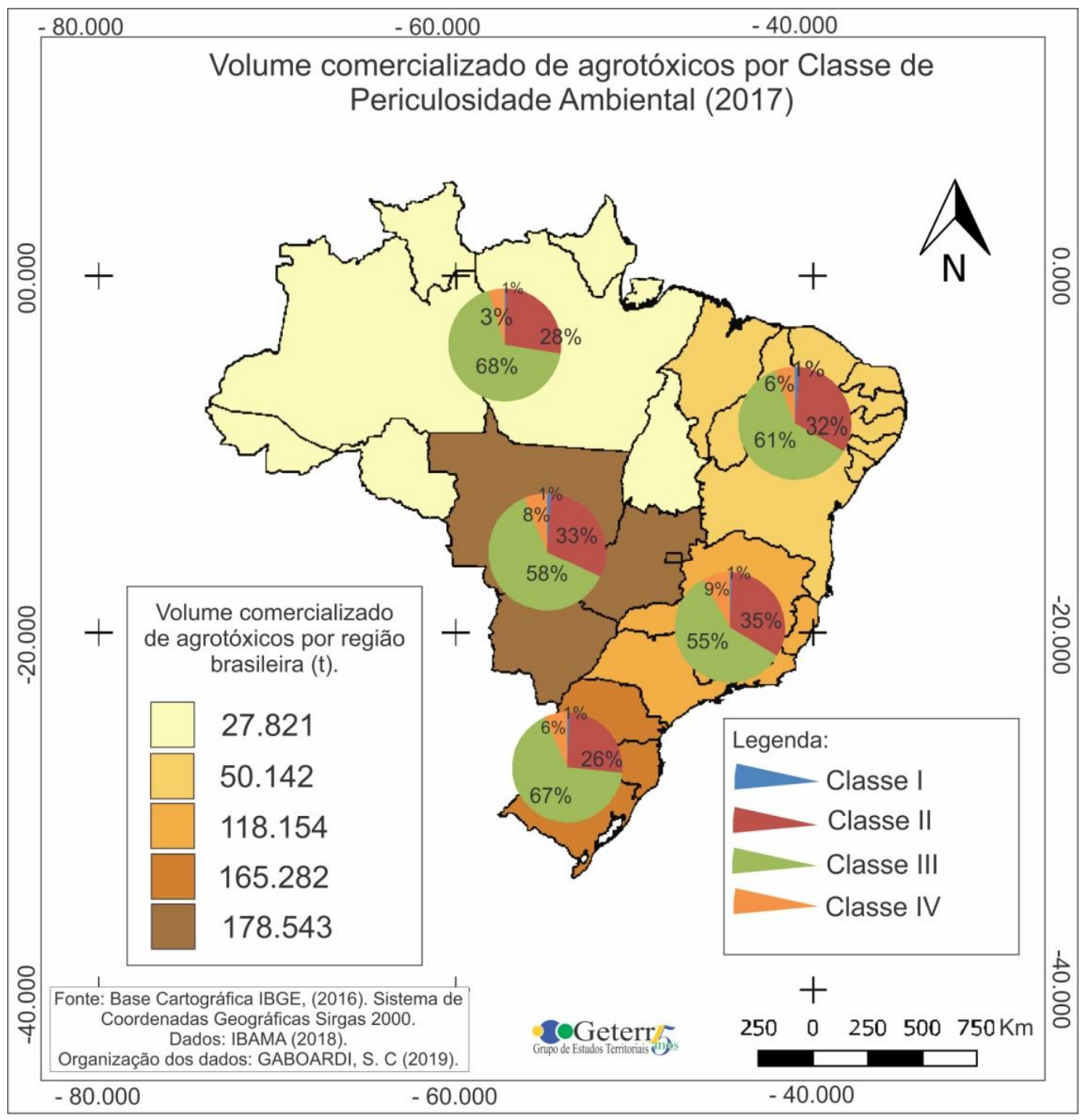

Fonte: IBAM A (2018). Org.: Autora, 2019.

Essa realidade se repete nos estados brasileiros, inclusive no estado de Santa Catarina, o qual comercializou, em 2017, 0,51\%dos produtos da Classe I, 25,32\%da Classe II, 69,49\%da Classe III e 4,66\%da Classe IV.

Segundo os dados do Censo Agropecuário (2017), em Santa Catarina, mais de 70\% do número total de estabelecimentos agropecuários utilizam agrotóxicos. Como se pode observar na Tabela 1, a mesorregião Oeste contém a maior quantidade de estabelecimentos agropecuários que utilizam agrotóxicos, seguida da mesorregião Vale 
do Itajaí. A mesorregião Norte ocupa a terceira posição. Já as mesorregiões em que menos estabelecimentos agropecuários utilizam agrotóxicos são: Mesorregião Sul, Mesorregião Serrana e Grande Florianópolis.

Tabela 1- Mesorregiões Catarinenses: Estabelecimentos Agropecuários que utilizaram agrotóxicos em 2017

\begin{tabular}{cc}
\hline Mesorregião Catarinense & $\begin{array}{c}\text { Número de estabelecimentos agropecuários } \\
\text { que utilizaram agrotóxicos }\end{array}$ \\
\hline Oeste & 60.921 \\
Vale do Itajaí & 20.483 \\
Norte & 18.308 \\
Sul & 14.377 \\
Serrana & 11901 \\
Grande Florianópolis & 5.945 \\
Total & 131935 \\
\hline
\end{tabular}

Fonte: Censo Agropecuário - IBGE (2017). Org.: Autora, 2019.

Na mesorregião Vale do Itajaí, localiza-se a M icrorregião de Rio do Sul, na qual dois campi do Instituto Federal Catarinense estão inseridos: Ibirama e Rio do Sul. Assim, para conhecer melhor a realidade da referida microrregião geográfica, no que se refere ao uso de agrotóxicos, apresenta-se a porcentagem do total de estabelecimentos agropecuários que utilizaram agrotóxicos em cada município da Microrregião de Rio do Sul no Mapa 3.

Entre os municípios da primeira classe nos quais $88 \%$ a $96 \%$ dos estabelecimentos utilizaram agrotóxicos no ano de 2017, estão: Aurora, Braço do Trombudo, Trombudo Central, Rio do Oeste e Presidente Nereu; na segunda classe, entre os municípios nos quais $79 \%$ a $87 \%$ dos estabelecimentos agropecuários utilizaram agrotóxicos, estão: Agronômica, Lontras, Ibirama, Taió, Mirim Doce, Salete, Vitor Meireles, Witmarsum e Dona Emma; na terceira classe, entre os municípios nos quais $70 \%$ a $78 \%$ dos estabelecimentos agropecuários utilizaram agrotóxicos, encontram-se: Presidente Getúlio, Rio do Campo, Pouso Redondo e Laurentino; a quarta classe apresenta os 
municípios nos quais $61 \%$ a $69 \%$ dos estabelecimentos agropecuários utilizaram agrotóxicos: Rio do Sul e J osé Boiteux.

De acordo com as informações da Pesquisa Agrícola Municipal (IBGE, 2016), as culturas que mais demandam agrotóxicos na M icrorregião de Rio do Sul são: milho, fumo, arroz, soja e cebola.

\section{Mapa 3 - Microrregião de Rio do Sul: estabelecimentos agropecuários que utilizaram agrotóxicos em 2017.}

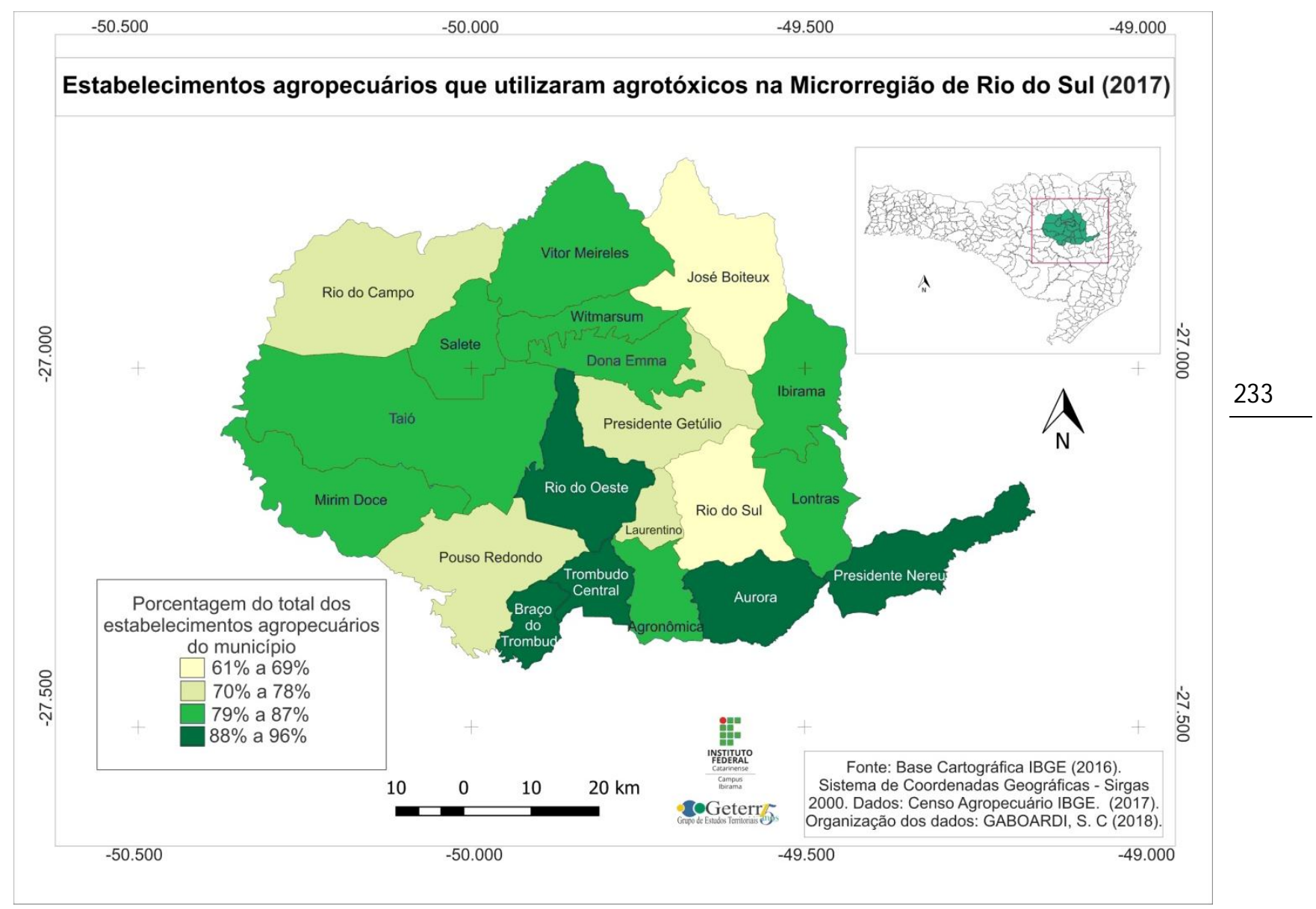

Fonte: Censo Agropecuário - IBGE (2017). Org.: Autora, 2018.

A partir da tabulação manual de dados acerca do volume comercializado do ingrediente ativo Glifosato no primeiro semestre de 2016 na M icrorregião de Rio do Sul, pode-se observar que agropecuárias dos municípios de Taió e Rio do Sul comercializaram, 
em um único semestre, 518.219 e 138.187 litros do ingrediente ativo Glifosato, respectivamente, conforme demonstrado no Mapa 4.

Mapa 4: Volume comercializado de Glifosato na Microrregião de Rio do Sul no primeiro semestre de 2016.

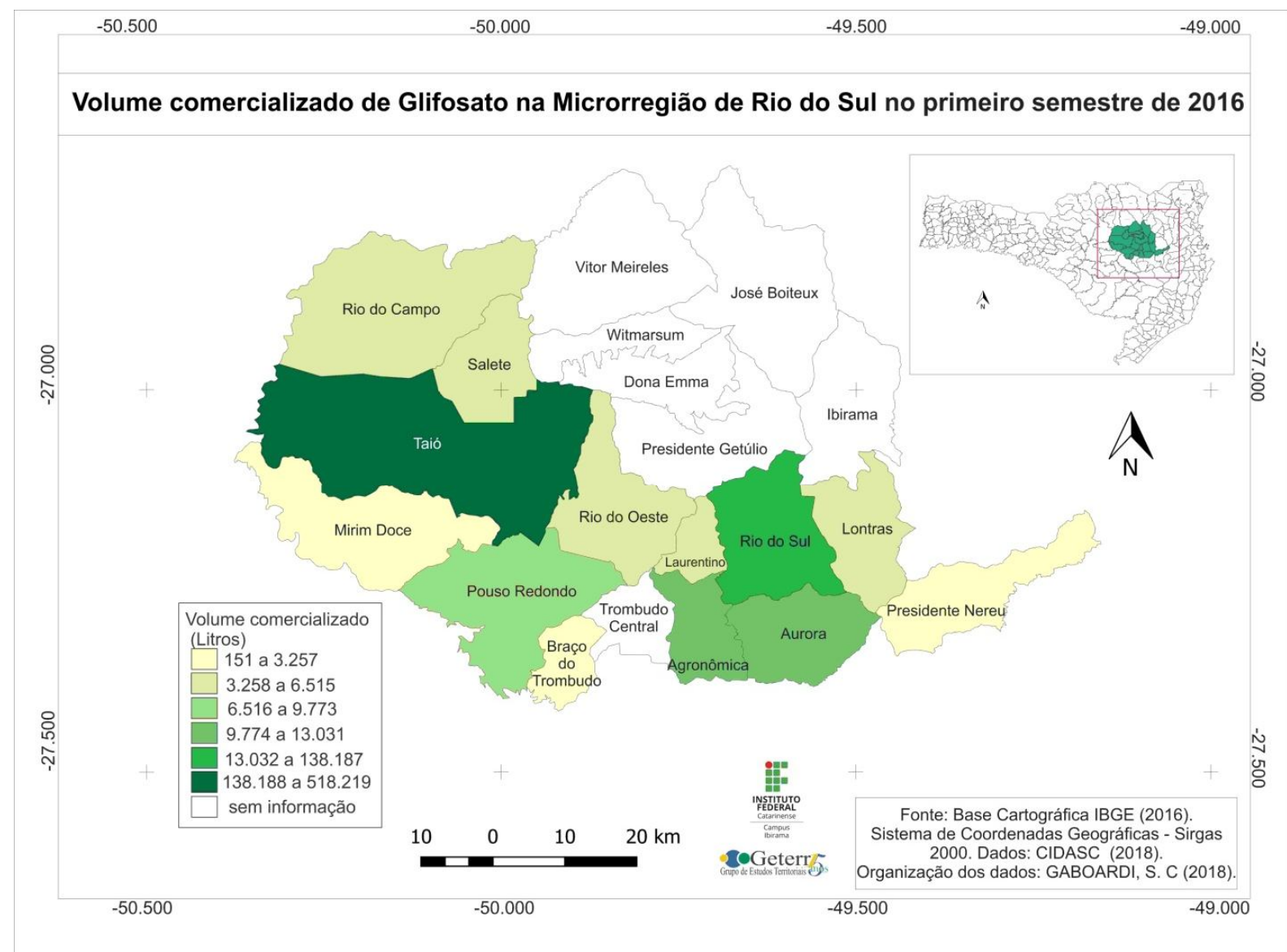

Fonte: CIDASC - Departamento Regional de Rio do Sul (2018). Org.: Autora, 2018.

Rio do Sul e Taió se destacam de tal maneira perante os demais municípios porque concentram agropecuárias que comercializam produtos para toda a Microrregião. 0 volume comercializado nos demais municípios foi: Aurora (13.030 litros), Agronômica (12.874 litros), Pouso Redondo (9.209 litros), Lontras (5.999 litros), Salete (5.907 litros), Rio do Oeste (5.330 litros), Laurentino (4.294 litros), Rio do Campo (3.998 litros), Presidente Nereu (2.128 litros), Braço do Trombudo (1.603 litros) e M irim Doce (151litros). 
Os municípios que aparecem em branco no mapa não possuem agropecuárias ou não foi obtida a informação no Departamento Regional da CIDASC Rio do Sul, visto que não há o monitoramento eficiente da utilização de agrotóxicos em Santa Catarina, impossibilitando-nos de fazer comparações entre municípios, micro e mesorregiões.

O Decreto Estadual 3.657/2005, que regulamenta a Lei Estadual o 11069/1998, a qual dispõe sobre o controle, o comércio, o uso, o consumo, o transporte e 0 armazenamento de agrotóxicos no estado, delega as atribuições de fiscalização e monitoramento do uso de agrotóxicos à Companhia Integrada de Desenvolvimento Agrícola de Santa Catarina (CIDASC). Contudo, até o presente momento, não há um sistema de monitoramento de agrotóxicos no estado. Em contato com o setor de Fiscalização de Insumos Agrícolas da CIDASC, no segundo semestre de 2018 , a informação obtida foi que não há dados disponíveis sobre volume comercializado por município, classe de uso, destinação por cultura, entre outros, uma vez que as informações devem ser tabuladas manualmente a partir do recebimento dos receituários agronômicos na forma de papel, o que seria inviável do ponto de vista dos recursos humanos disponíveis.

Os receituários agronômicos, bem como um relatório de controle de estoque enviado semestralmente pelas agropecuárias que comercializam agrotóxicos, são armazenados nos Departamentos Regionais da CIDASC por um período de dois anos. Os relatórios semestrais são encaminhados impressos por loja agropecuária e não possuem uma padronização. Assim, existem diversas variações de um mesmo produto. Esses relatórios não são disponibilizados, nem divulgados pela CIDASC. Por isso, para ter acesso a eles, é necessário ir até cada um dos dezenove Departamentos Regionais.

Ainda segundo as informações obtidas no setor de Fiscalização de Insumos Agrícolas, a CIDASC implantará um sistema de monitoramento de agrotóxicos semelhante ao adotado no estado do Paraná (o Siagro), contudo, dados confiáveis a respeito da situação dos agrotóxicos em Santa Catarina só poderão ser consultados a partir do ano de 2020. 
Enquanto isso, o ambiente e a saúde dos catarinenses estão sob sério risco de contaminação. Em março de 2019, o Ministério Público de Santa Catarina divulgou uma pesquisa sobre a presença de agrotóxicos na água de abastecimento público de 90 municípios de Santa Catarina e identificou que 22 recebem água com residual de agrotóxicos.

Segundo a pesquisa encomendada pelo Ministério Público e realizada na Universidade Federal de Santa Catarina, foram encontradas 17 diferentes substâncias e, destas, sete são proibidas nos países membros da União Europeia pelos malefícios que causam ao ambiente e à saúde dos seres humanos.

Entre os 22 municípios com água contaminada, oito pertencem à mesorregião Vale do Itajaí (Rio do Sul, Ibirama, Ituporanga, Taió, Ilhota, Itapema, Balneário Camboriú e Balneário Piçarras), sete pertencem à mesorregião Norte (Schroeder, Mafra, Massaranduba, Joinville, Porto União, Rio Negrinho e Itaiópolis), seis pertencem à mesorregião Sul (Balneário Gaivota, Tubarão, Orleans, Balneário Rincão, Gravatal e Jaguaruna) e um município pertence à mesorregião Oeste (Coronel Freitas) (MPSC, 2019).

Em abril de 2019, foi publicada uma investigação acerca da presença de agrotóxicos na água potável dos municípios brasileiros entre os anos de 2014 e 2017, pesquisa esta realizada pelas agências de jornalismo investigativo Repórter Brasil e Agência Pública, em parceria com a Organização Não-Governamental Public Eye, a qual é sediada na Suíça. Os dados que foram divulgados são oriundos do Sistema de Informação de Vigilância da Qualidade da Água para Consumo Humano (Sisagua), do Ministério da Saúde.

O Sisagua reúne os resultados de testes que medem a presença de 27 agrotóxicos na água que abastece as cidades brasileiras. Todas as informações devem ser enviadas pelas empresas de abastecimento, visto que é determinado em lei que os fornecedores de água devem realizar testes a cada seis meses e apresentar os resultados ao Governo Federal (REPORTER BRASIL, 2019). 
Ao selecionar os 20 municípios da Microrregião de Rio do Sul, sete deles não possuem informações. Os outros 13 municípios apresentaram todos os 27 agrotóxicos testados detectados na água potável e, desses, em 10 municípios foram encontrados resíduos acima do limite máximo permitido na União Europeia, a qual é referência internacional pelo rigor na determinação dos limites máximos (LMR) (ver tabela 2).

Tabela 2 - Número de agrotóxicos detectados na água nos municípios da Microrregião de Rio do Sul.

\begin{tabular}{lccc}
\hline \multicolumn{1}{c}{ MUNICÍPIO } & $\begin{array}{c}\text { TOTAL DE AGROTÓXICOS } \\
\text { DETECTADOS }\end{array}$ & $\begin{array}{c}\text { ACIMA DO LMR NO } \\
\text { BRASIL }\end{array}$ & $\begin{array}{c}\text { ACIMA DO LMR NA } \\
\text { U.E }\end{array}$ \\
\hline Braço do Trombudo & 27 & Zero & 23 \\
Dona Emma & 27 & Zer0 & Sem informação \\
\hline Ibirama & 27 & Zero & 1 \\
\hline Mirim Doce & 27 & Zero & 16 \\
Pouso Redondo & 27 & Zero & 15 \\
Presidente Nereu & 27 & Zero & 1 \\
Rio do Campo & 27 & Zero & 24 \\
Rio do Oeste & 27 & Zero & Sem informação \\
Rio do Sul & 27 & Zero & 24 \\
Salete & 27 & 1 & 16 \\
Taió & 27 & Zero & 16 \\
Trombudo Central & 27 & Zero & 15 \\
Vitor M eireles & 27 & Zero & Sem informação \\
\hline
\end{tabular}

Fonte: REPORTER BRASIL; AGÉNCIA PÚBLICA; PUBLIC EYE (2019). Obs.: Municípios faltantes não possuem informação.

A ampla comercialização e utilização de agrotóxicos, aliada à alta permissividade do limite de resíduos, apesar do desconhecimento dos riscos associados à utilização de alguns produtos, causam o agravamento dos casos de contaminação humana e ambiental em Santa Catarina e, também, no país como um todo.

A presença de resíduos de agrotóxicos na água de abastecimento público revela que a exposição aos agrotóxicos transcende as áreas de cultivo e o círculo das famílias agricultoras. As populações residentes próximas às lavouras, bem como os consumidores 
dos produtos com resquícios de agrotóxicos, passam a estar expostos aos efeitos nocivos dos agentes químicos.

No Brasil, além da contaminação humana, as commodities, como a soja, concorrem no mercado internacional à custa da intensificação do desmatamento, da perda da diversidade biológica e da degradação dos solos e da água. Nesse sentido, os grupos sociais que vivem na periferia econômica do "desenvolvimento" acabam por arcar com as maiores cargas negativas nos ambientes em que vivem e trabalham, caracterizando a problemática dos agrotóxicos como um caso de injustiça ambiental (PORTO, 2007). Ou ainda, como destaca Porto-Gonçalves (2006), a geografia desigual do uso desses insumos revela o modo desigual como se valorizam os lugares, as regiões, os países, seus povos e culturas.

A estrutura político-econômica que dá sustentação ao agronegócio, desde a mídia hegemônica, grupos transnacionais e grandes "cooperativas", éa maior responsável pela produção dependente de agrotóxicos perigosos.

No Brasil, a opção do governo tem sido a de adotar o agronegócio como um modo hegemônico de produção agrícola. Nesse sentido, o Congresso Nacional e a Bancada Ruralista, a qual é composta por deputados que possuem altos financiamentos de campanha pela indústria química do agronegócio, vêm se organizando, há muitos anos, para articular estratégias que visam a flexibilizar ainda mais a entrada e o uso de agrotóxicos perigosos no país, colocando em cheque um sistema regulatório de registros e fiscalizações que já é fragilizado, se comparado ao de outras nações.

0 exemplo mais claro disso é o Projeto de Lei (PL) 6.299/2002, também conhecido como "PL do Veneno", o qual substitui a Lei 7.802 de 1989. A este PL, foram apensados outros 30 projetos que tramitaram no Congresso entre 1999 e 2017', os quais abordam a

\footnotetext{
${ }^{1}$ Apensados: PL 2495/2000 (6), PL 3125/2000 (4), PL 5884/2005, PL 6189/2005 (1), PL 4933/2016, PL 3649/2015, PL 5852/2001; PL 1567/2011 (1), PL 4166/2012; PL 1779/2011; PL 3063/2011; PL 1687/2015 (4), PL 3200/2015, PL 49/2015 (2), PL 371/2015, PL 461/2015; PL 958/2015; PL 7710/2017; PL 8026/2017; PL 6042/2016; PL 713/1999 (5), PL 1388/1999, PL 7564/2006, PL 4412/2012 (1), PL 2129/2015, PL 5218/2016; PL 5131/2016 (1), PL 10552/2018; PL 8892/2017; PL 9271/2017.
} 
temática dos agrotóxicos e que, em sua maioria, visam a flexibilizar o marco legal existente, alterando profundamente o sistema normativo de agrotóxicos no país.

Entre as mudanças mais polêmicas, está o processo de aprovação e registro de um novo agrotóxico, sendo que, atualmente, é preciso a autorização do IBAM A, da ANVISA e do M APA, o que viabiliza um maior controle do Estado em relação à análise em diferentes dimensões, seja ambiental, saúde ou eficácia agronômica. A proposta do PL do Veneno é criar uma Comissão Técnica Nacional de Fitossanitários (CTNFito), a qual terá a finalidade de aprovar ou não o registro de novos produtos. O IBAM A e a ANVISA possuem cadeira nessa comissão, mas não terão poder de veto nas avaliações de liberação de agrotóxicos.

Junto às alterações propostas no projeto de lei, está a mudança de denominação: assim, passará de agrotóxicos para defensivos fitossanitários e produtos de controle ambiental. Uma confusão conceitual que oculta situações de risco ao comunicar falsa segurança dos produtos químicos.

Como observa Porto (2018), o PL 6.299 assume a primazia dos interesses econômicos do agronegócio, no lugar da defesa da saúde e do meio ambiente. Dessa forma, conforme destaca o autor, vivemos um retrocesso civilizatório, caminhando na direção contrária a vários países com maior consciência ecológica, onde há maior incentivo de alimentos saudáveis.

Nesse sentido, a fragilização no processo de registro e fiscalização de agrotóxicos no Brasil deve, também, comprometer a posição do país na disputa por mercados. As barreiras sanitárias podem dificultar a entrada de produtos em desacordo com os limites máximos de resíduos permitidos nos países de destino. Exemplo disso é o caso das autoridades russas que, no início de 2019, encontraram vestígios de glifosato superiores aos limites estabelecidos no país. O Rosselkhoznadzor, que corresponde ao Ministério da Agricultura da Rússia, justificou o alerta devido ao alto grau de toxicidade do ingrediente ativo em humanos e animais (ROSSELKHOZNADZOR, 2019). 
A expansão das monoculturas, com seus agroecossistemas fragilizados e desequilibrados, faz com que haja a dependência da utilização de fertilizantes sintéticos, inseticidas, herbicidas, fungicidas, acaricidas, entre outros biocidas, que são amplamente utilizados no intuito de exterminar todos os fatores que possam comprometer a alta produtividade.

O agronegócio em questão possui racionalidade econômica ao ponto de dar nova significação ao alimento, transformando-o em mercadoria. Os agroecossistemas simplificados por meio das monoculturas passam a ser dependentes de insumos externos e isso leva à contaminação dos recursos hídricos, do solo, do ar, além de levar à diminuição da diversidade biológica. Como destaca Porto-Gonçalves (2006), esse conjunto de fatores faz saltar à vista as limitações ecológicas e o meio ambiente, também, passa a ser entendido como mercadoria diante das intencionalidades das grandes corporações.

Todavia, essa não é a preocupação do agronegócio brasileiro, seu maior objetivo é a extração de lucro e essa é a principal finalidade da agricultura capitalista. Contudo, a promessa de "eliminar a fome no mundo", bastante difundida durante o período conhecido como Revolução Verde, ainda se apresenta em alguns discursos, aliado, especialmente no Brasil, à falácia do "PIB do agronegócio", que, segundo Oliveira (2016), quer passar para a sociedade brasileira uma ideia de grandeza que a agropecuária brasileira não tem, já que, na verdade, são somados os dados da indústria e dos serviços àqueles da agropecuária.

Ainda segundo Oliveira (2016), existe, para se justificar a "importância" e perpetuação do agronegócio, um método próprio de quantificação econômica que acaba por inflar a representação do Produto Interno Bruto, agrupando empresas de insumos (agrotóxicos, sementes, máquinas agrícolas), agricultura, indústria de alimentos, distribuição, transportes, combustíveis, armazenamento, serviços portuários, entre outras. 
Evidentemente, a mídia hegemônica, também, tem um papel substancial na divulgação desses ideais. A campanha publicitária “Agro é Tech, Agro é Pop, Agro é Tudo", iniciada no ano de 2016 na Rede Globo, tenta construir uma imagem extremamente positiva do agronegócio brasileiro, mas oculta as contradições da cadeia produtiva, como as precárias condições de trabalho, o fato de que a fome não foi erradicada no país ${ }^{2}$ e que 0 agronegócio levou o Brasil a obter o título de maior consumidor de agrotóxicos do mundo, trazendo sérias complicações para a saúde dos consumidores e trabalhadores rurais, bem como para o meio ambiente.

\section{Considerações Finais}

O elevado uso de agrotóxicos no Brasil tem promovido amplos debates no âmbito científico e político, visto que a utilização desses produtos pode causar efeitos negativos no ambiente e na saúde humana.

Conforme Carneiro (2015), os principais grupos afetados pelos efeitos dos agrotóxicos são os agricultores e suas famílias, que estão em contato direto com os produtos, os moradores de áreas próximas de lavouras e os consumidores dos alimentos e água contaminados por pesticidas.

Como destacado no presente artigo, até mesmo agrotóxicos como o Paraquate, o qual teve comprovado seu potencial de mutagenicidade e Doença de Parkinson, só será banido na segunda metade do ano de 2020. 0 ingrediente ativo Glifosato, classificado pela Organização M undial da Saúde como provavelmente cancerígeno aos seres humanos e, pelo IBAM A, como produto perigoso ao meio ambiente, continua sendo o líder de vendas no país.

\footnotetext{
${ }^{2}$ Segundo o relatório da FAO e OPS, intitulado " 2017. Panorama de la seguridad alimentaria y nutricional en América Latina y en Caribe", ainda há uma taxa de subalimentação que corresponde a 2,5\%da população brasileira, mas, segundo o relatório, com investimentos adequados em políticas públicas voltadas às populações mais vulneráveis, a erradicação poderá ser cumprida em 2030.
} 
Apesar de terem crescido as campanhas contra o uso de agrotóxicos, como, por exemplo, a Campanha Permanente Contra os Agrotóxicos e Pela Vida, e as pesquisas divulgadas pela Fundação Oswaldo Cruz (FIOCRUZ), pelo Instituto Nacional do Câncer (INCA) e pela Associação Brasileira de Saúde Coletiva (ABRASCO), entre outros institutos de pesquisa e sociedades científicas, o volume comercializado de agrotóxicos vem aumentando a cada ano. Entre 2009 e 2017, esse volume cresceu 80\%no Brasil e, em Santa Catarina, o aumento foi de $107 \%$

Apesar de o IBAMA ter divulgado o volume comercializado por Unidade da Federação, em Santa Catarina, não há monitoramento eficiente do uso de agrotóxicos por município, por culturas ou classe de uso (herbicida, inseticida, fungicida...). Isso significa, conforme afirma Bombardi (2013), que vivenciamos, no campo, uma forma silenciosa de violência, a qual tem como pano de fundo as empresas produtoras de agroquímicos interessadas na apropriação da renda da terra no país. Acrescenta-se, ainda, a indiferença por parte do Estado, no que se refere ao interesse em monitorar os efeitos que tais produtos estão causando no ambiente e na saúde humana.

A própria Organização das Nações Unidas (ONU) reconheceu, em informes publicados em 2017 e 2018, que a dependência de agrotóxicos perigosos é uma solução de curto prazo que afeta o direito à alimentação adequada e o direito à saúde das gerações presentes e futuras.

Dessa forma, diante dos dados apresentados no presente trabalho, conclui-se que o meio ambiente está sendo entendido como mercadoria (PORTO-GONÇALVES, 2006) diante das intencionalidades do setor do agronegócio; e que o investimento em práticas sustentáveis é necessário para assegurar a saúde humana e evitar maiores ofensivas ao ambiente. 


\section{Agradecimentos}

Ao Campus Ibirama do Instituto Federal Catarinense, pelo apoio financeiro. À Maria Helena Cipriani, bolsista do projeto. À geógrafa Raquel Meira, por disponibilizar as bases cartográficas. Ao professor Luciano Candiotto, pelo apoio na elaboração do projeto.

\section{Referências}

AGÊNCIA NACIONAL DE VIGILÂNCIA SANITÁRIA (ANVISA). Anvisa finaliza reavaliação toxicológica do Paraquate. Disponível em: «ttp://portal.anvisa.gov.br/rss//asset_publisher/Zk4q6UQCj9Pn/content/anvisa-finaliza-reavaliacao-toxicologicado-paraquate/219201?inheritRedirect $=$ false $>$. Acesso em: 12/07/2018.

BOM BARDI, L. M . Agrotóxicos: uma arma silenciosa contra os direitos humanos. Direitos Humanos no Brasil, 2013: Relatório da Rede Social de Justiça e Direitos Humanos. São Paulo, 2013.

BRASIL. Decreto 4.074 de 04 de janeiro de 2002. Regulamenta a Lei no 7.802, de 11 de julho de $\quad 1989 . \quad$ Disponível em: «ttp://www.planalto.gov.br/ccivil_03/decreto/2002/d4074.htm>. Acesso em 12/07/2018.

CARNEIRO, F. F.; AUGUSTO, L. G. S.; RIGOTTO, R. M.; FRIEDRICH, K.; BÚRIGO, A. C. (Orgs.). Dossiê ABRASCO: um alerta sobre os impactos dos agrotóxicos na saúde. Rio de Janeiro: EPSJ V; São Paulo: Expressão Popular, 2015.

DUARTE, P. A. Fundamentos de Cartografia. Florianópolis: UFSC, 2002.

INTERNATIONAL AGENCY FOR RESEARCH ON CANCER - IARC. Monographs on the evaluation of carcinogenic risks to humans. Some organophosphate insecticides and herbicides, v. 112, 2017.

INSTITUTO BRASILEIRO DE GEOGRAFIA E ESTATÍSTICA - IBGE. Produção Agrícola Municipal 2016. Disponível em: < http://www2.sidra.ibge.gov.br/bda/pesquisas/pam/default.asp?o=30\&i=P>. Acesso em: 13/07/2018. 
INSTITUTO BRASILEIRO DE GEOGRAFIA E ESTATÍSTICA - IBGE. Censo Agropecuário 2017 Resultados preliminares. Disponível em: «ttps://censos.ibge.gov.br/agro/2017/>. Acesso em: 15/03/2019.

INSTITUTO BRASILEIRO DO M EIO AM BIENTE E DOS RECURSOS NATURAIS RENOVÁVEIS - IBAM A. Produtos agrotóxicos e afins comercializados em 2009 no Brasil: uma abordagem ambiental. Brasília: Ibama, 2010.

INSTITUTO BRASILEIRO DO M EIO AM BIENTE E DOS RECURSOS NATURAIS RENOVÁVEIS - IBAMA. Relatórios de Comercialização de Agrotóxicos. Disponível em: < http://www.ibama.gov.br/agrotoxicos/relatorios-de-comercializacao-deagrotoxicos $>$. Acesso em: 22/01/2018.

MARTINELLI, M. Curso de Cartografia Temática. São Paulo: Contexto, 1991

MINISTÉRIO PÚBLICO DE SANTA CATARINA - MPSC. Levantamento do MPSC aponta que 22 municípios do estado recebem água com agrotóxicos. Disponível em: «ttps://www.mpsc.mp.br/noticias/levantamento-do-mpsc-aponta-que-22municipios-do-estado-recebem-agua-com-agrotoxicos>. Acesso em: 27/03/2019.

OLIVEIRA, A. U. A mundialização da agricultura brasileira. São Paulo: Iãnde Editorial, 2016.

ORGANIZAÇÃO DAS NAÇÕES UNIDAS - ONU. Informe de la Relatora Especial sobre el derecho a la alimentación. Disponível em: বttps://www.ohchr.org/Documents/lssues/Food/A.HRC.19.59.Add.5_SP.pdf>. Acesso em: 17 de junho de 2018.

PORTO-GONÇALVES, C. W. A Globalização da Natureza e a Natureza da Globalização. Rio de J aneiro: Civilização Brasileira, 2006.

PORTO, M. F. Agrotóxicos, saúde coletiva e insustentabilidade: uma visão crítica da ecologia política. Ciência e Saúde Coletiva, v. 12, n. 1, p. 15-24, 2007.

PORTO, M. F. 0 trágico Pacote do Veneno: lições para a sociedade e a Saúde Coletiva. Cadernos de Saúde Pública, n, 34, p. 01-05, 2018.

REPORTER BRASIL. "Coquetel" com 27 agrotóxicos foi achado na água de 1 em cada 4 municípios. Disponível em: https://reporterbrasil.org.br/2019/04/coquetel-com-27agrotoxicos-foi-achado-na-agua-de-1-em-cada-4-municipios/. Acesso em: 08/05/2019. 
ROSSELKHOZNADZOR - Federal Service for Veterinary and Phytosanitary Surveillance. Julia Shvabauskene Negotiated with the Representatives of Brazilian Competent Authority on Soya Bean Import to Russia. Disponível em: http://www.fsvps.ru/fsvps/news/29304.html?_language=en. Acesso em: 08/05/2019.

SINDICATO NACIONAL DA INDÚSTRIA DE PRODUTOS PARA A DEFESA VEGETAL SINDIVEG. 0 que você precisa saber sobre defensivos agrícolas. Disponível em: বttp://sindiveg.org.br/wpcontent/uploads/2018/08/oquevoceprecisasabersobredefensivosagricolas.pdf $>$. Acesso em: 17/01/2019.

SPADOTTO, C. A.; GOMES, M. A. F. Agrotóxicos no Brasil. Disponível em: বtttp://www.agencia.cnptia.embrapa.br/gestor/agricultura_e_meio_ambiente/ar vore/CONTAG01_40_210200792814.html>. Acesso em 13/07/2018.

Shaiane Carla Gaboardi é Doutoranda em Geografia pela Universidade Estadual do Oeste do Paraná (UNIOESTE), Campus de Francisco Beltrão, e Professora do Instituto Federal Catarinense (IFC), Campus Ibirama. E-mail: shaiane_carla@ hotmail.com

Artigo enviado em 01/04/2019 e aprovado em 10/05/2019. 